\title{
Effects of a Physical Exercise Program on Patients Affected with Fibromyalgia
}

\author{
Glòria Sauch Valmaña ${ }^{1,2} \mathbb{D}^{\mathbb{D}}$, Josep Vidal-Alaball',2, \\ Pere Roura Poch ${ }^{3}$, Jacobo Mendiroz Peña ${ }^{1,2}$, Robert Panadés Zafra ${ }^{4}$, \\ Francesc Xavier Cantero Gómez ${ }^{5}$, Anna Ruíz Comellas ${ }^{2,6}$, \\ and David Barranco Reixachs ${ }^{7}$
}

\begin{abstract}
Background: physical activity has been used for a number of years in the treatment of fibromyalgia (FM). The main objective of this study is to compare the effects of physical activity on 2 groups of women diagnosed with FM in terms of pain, quality of life and the impact of the condition on their daily lives. Methods: this was a randomized clinical trial to assess the effects of physical activity performed by subjects assigned to one of 2 groups on the scores of 3 questionnaires, the pain Visual Analog Scale (EVA), the Fibromyalgia Impact Questionnaire (FIQ) and the SF-36 health questionnaire administered before and after the intervention. Results: A total of 24 subjects were randomly assigned to each of the 2 study groups. No significant differences were found after the program of 3 months of physical activity ended. Conclusions: Our study shows that a physical activity program with duration of less than 3 months does not significantly improve any of the factors studied.
\end{abstract}

\section{Keywords}

physical activity, exercise, fibromyalgia, pain, quality of life

\section{Introduction}

FM is a condition which appears at an early age which has a significant impact on the health of people who suffer from it, greatly affecting their quality of life. ${ }^{1}$ According to the study of the prevalence of rheumatic diseases (EPISER) of the Spanish Society of Rheumatology, it is estimated that in Spain between 2 and $4 \%$ of the population suffer from it, with its prevalence being greater in women than in men. ${ }^{2}$ The condition is characterized by chronic pain, fatigue, mood impairment and alterations in sleep patterns which lead to a decrease in physical capacity and a reduction in the ability to carry out every day activities.

The cause of the condition remains unknown and no objective test exists to confirm a diagnosis. Diagnosis is based on the criteria defined by the American College of Rheumatology (ACR) in $1990,{ }^{3}$ according to which fibromyalgia is present when a patient has experienced pain for 3 months or more in the body's 4 quadrants, together with greater sensitivity to pain when pressure is applied to 11 of the 18 so-called tender points. These points are mainly located in the arms, buttocks, chest, knees, lower back, neck, rib cage, shoulders and thighs. ${ }^{4}$
The new diagnostic criteria for FM released in 2010 and reviewed in 2016, are based on the Widespread Pain Index

\footnotetext{
'Unitat de Suport a la Recerca Catalunya Central, Fundació Institut Universitari per a la recerca a l'Atenció Primària de Salut Jordi Gol i Gurina, (IDIAPJGol), Barcelona, Spain

${ }^{2}$ Health Promotion in Rural Areas Research Group, Gerència Territorial de la Catalunya Central, Institut Català de la Salut, Sant Fruitós de Bages (Barcelona), Spain

${ }^{3}$ Consorci Hospitalari de Vic., Vic, (Barcelona), Spain

${ }^{4}$ Centre d'Atenció Primària Anoia Rural. Institut Català de la Salut, Catalunya Central, Igualada, (Barcelona), Spain

${ }^{5}$ Centre d'Atenció Primària Igualada Urbà. Institut Català de la Salut, Catalunya Central, Igualada (Barcelona), Spain

${ }^{6}$ Centre d'Atenció Primària Sant Joan de Vilatorrada. Institut Català de Salut, Catalunya Central (Barcelona), Spain

${ }^{7}$ Universitat de Lleida. Campus Igualada, Igualada (Barcelona), Spain
}

Received 10 July 2020; revised September 4 2020; revised manuscript accepted 7 September 2020

\section{Corresponding Author:}

Glòria Sauch Valmaña, Gerència Territorial de la Catalunya Central, Institut Català de la Salut, c/ Pica d'Estats 13-15, Sant Fruitós del Bages, Barcelona 08272, Spain.

Email: gsauch.cc.ics@gencat.cat 


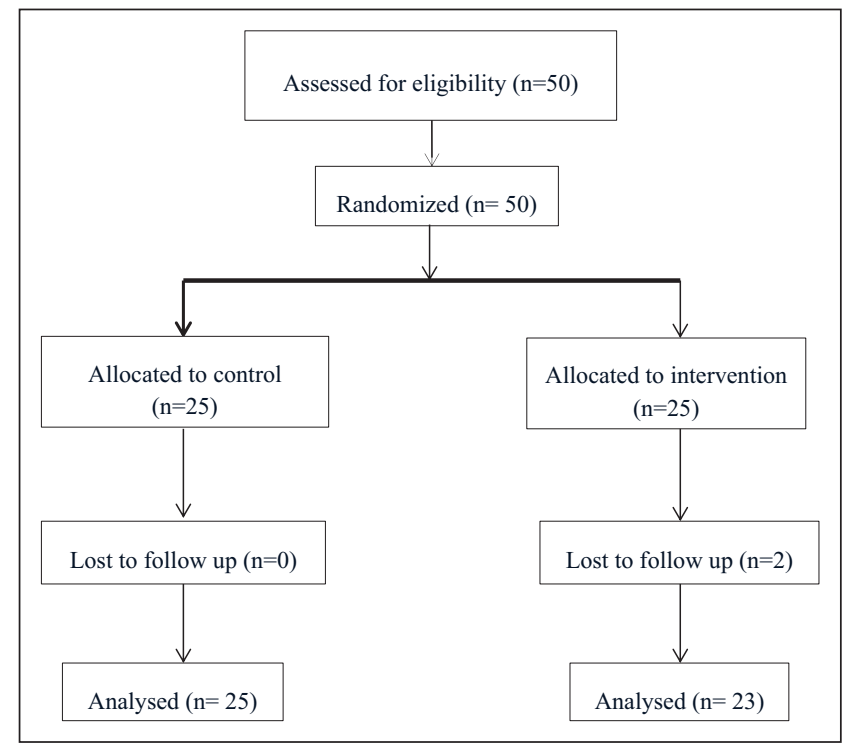

Figure I. Flowchart of patient selection.

(WPI) and the Symptom Severity Score (SS-Score). This new method does not require physical examination and facilitates its diagnosis to primary care professionals. ${ }^{5}$

Individuals diagnosed with FM frequently consult a doctor, which represents a significant cost for the health system. This means it is worthwhile investigating the benefits of alternatives to pharmacological treatments, which have the potential to be less costly and more effective. ${ }^{6}$ To date, no known treatment has been found to be consistently effective in treating the condition. This has raised the possibility of using combination therapy, which typically involves a combination of medication and controlled exercise programs. ${ }^{7}$ As a result, in 2006, the Generalitat [the Catalan government] of Catalonia's Ministry of Health, in collaboration with Rheumatology and Mental Health specialists, drew up a treatment plan for individuals affected by central pain syndromes based on health education and physical exercise combined with medication. ${ }^{8}$

The interventions proposed in this plan were intended to empower the patient, providing them with the right tools to be able to self-manage their symptoms in order that they can learn to live with the condition. Physical exercise has been seen to be an important component in the treatment of FM and since its impact on psychological well-being is well-established, it has been shown in several studies as a means of reducing medication. ${ }^{9-11}$ It has been observed that patients who perform more physical exercise experience a higher level of well-being, compared to those who do not undertake any, whose self-perception of their health is lower. It has also been shown that physical exercise is highly effective in reducing pain and fatigue.

People with FM have lower aerobic endurance and muscle strength; these symptoms may limit their ability to perform their activities of daily living.
Various studies have shown that individuals ought not to engage in high intensity motor skills such as strength training, since these may worsen their physical well-being, causing them to end up abandoning the study.

The objective of this study was to evaluate the benefits of a 12-week targeted physical activity program for people with fibromyalgia.

\section{Methods}

A randomized, multi-center, clinical trial composed of 2 groups response variables and a 12 weeks follow up.

The subjects recruited for the study were all women between the ages of 40 and 75 who, at the time of recruitment, had a diagnosis of FM, ICD-10-CM code M79.7 according to the computerized medical records of the Catalan Health Institute (ICS) of 4 Primary Health Care Teams (PHC) belonging to the Anoia region; Igualada Urbà, Vilanova del camí, Santa Margarita de Montbui and Anoia Rural.

Individuals were excluded from the study if they were pregnant were unable to participate in the physical activity program or if they were participating in other physical activity programs (pilates, aquagym, dance, etc).

\section{Sample Size}

In total 50 patients were selected, the sample size corresponds to the expected proportion of subjects with a score of 7 on the EVA scale and a score of 32 on the SF-36 questionnaire, a confidence interval of $95 \%$ and power of $80 \%$. Estimating that with the proposed intervention it could lower 2 points in both EVA scale and SF-36 questionnaire, we obtained a sample size of $n=32$.

The subjects chosen were contacted by telephone and given an appointment at their respective PHC where they completed 3 questionnaires prior to the intervention and 3 upon completion. The interviewer did not know in which group the participants were assigned. The subjects were randomly assigned to 2 groups by means of the SPSS v.18 (SPSS Inc., Chicago, USA) statistical program: The control group, who did not complete the physical activity program (CG $\mathrm{n}=25)$ and the intervention group, who performed physical activity 2 days a week for 3 months $(I G n=25)$. Two patients in the IG expressed their desire to leave the study for personal reasons not related to the study; the other participants attended $80 \%$ of the sessions. The professional who directed the sessions noted in a notebook the attendance. The final study sample was 48 participants (Figure 1).

\section{Intervention}

The intervention group: engaged in a therapeutic physical activity program involving aerobic endurance and strength and balance work for 2 days a week over a 12 -week period, with each session lasting 90 minutes. Both the intervention 
group and the control group separately completed the various baseline surveys which were part of the study. Once the intervention was over, they answered them again, also separately.

The classes were led by an experienced physiotherapist who followed the physical exercise guidelines established by the American College of Sports Medicine (ACSM), although the intensity of the exercises was adapted to the participants' tolerance levels.

\section{Outcome Measures}

The patients were evaluated by the same individual at the beginning and the end of the program.

The visual analog scale (VAS) was used to evaluate pain, with a score of 0 to 10 . The Spanish version of the SF-36 questionnaire was used to assess their perceived state of health. It includes 8 variables: vitality, physical functioning, bodily pain, general health perceptions, physical role functioning, emotional role functioning, social role functioning and mental health. The procedures used to obtain the results followed the Manual de puntuación de la versión española del cuestionario SF-36 [Guidelines for Scoring the Spanish Version of the SF-36 Questionnaire]. ${ }^{12}$ The impact of the condition was measured using the Spanish version of the Fibromyalgia Impact Questionnaire (FIQ).${ }^{13}$ The FIQ measures physical functioning, ability to undertake work and general well-being, with a score from 0 to 80 . To calculate the score of the Spanish version the researchers used the calculation and procedures recommended by Monterde in the validation procedures of the Spanish questionnaire. ${ }^{14}$

\section{Statistical Analysis}

The quantitative variables were described using summary statistics and statistical dispersion and the qualitative variables were described by their absolute frequencies and percentage. The bivariate analysis was based on the behavior of the quantitative variables (according to whether they follow a normal distribution or not) and the Wilcoxon test was used for the nonparametric comparison of matched paired data when comparing data from the start and the finish of the intervention.

The significance level has been set at the probability of error lower than $5 \%(P<.05)$.

SPSS v.23 software (SPSS Inc., Chicago, USA) was used for the statistical analysis.

\section{Results}

The study included 48 women diagnosed with fibromyalgia who were invited to participate in a clinical trial involving physical activity. Twenty-five were randomized to the control wing and 23 to the intervention wing.

The women who were randomized into the 2 groups (control and intervention) were homogenous in terms of
Table I. Age of the Participants.

\begin{tabular}{lccc}
\hline Group & Average & $\mathrm{N}$ & Standard deviation \\
\hline Control & 52.96 & 25 & 7.696 \\
Intervention & 55.01 & 23 & 7.726 \\
Total & 53.95 & 48 & 7.698 \\
\hline
\end{tabular}

Table 2. Years of Evolution of the Disease.

\begin{tabular}{lccc}
\hline Group & Average & $\mathrm{N}$ & Standard deviation \\
\hline Control & 5.32 & 25 & 3.80 \\
Intervention & 5.30 & 23 & 4.93 \\
Total & 5.31 & 48 & 4.33 \\
\hline
\end{tabular}

age, years they had had the condition, baseline pain score, summary indexes for physical and mental health on the SF-36 questionnaire and their FIQ questionnaire score.

At the time of inclusion, the women had an average age of 53'95 years $\left(\mathrm{SD} \pm 7^{\prime} 69\right)$. A statistical analysis with Student's T test did not identify significant differences between the ages of both trial groups (Table 1).

The average years of evolution of the disease was 5.31 years $(\mathrm{SD} \pm 4.33)$ (Table 2$)$.

A statistical analysis with Mann-Whiteny $U$ test did not identify significant differences between the 2 trial groups (Table 3).

Once the trial had ended, the results showed that there were no significant differences in either group before and after the intervention with respect to the EVA, FIQ and SF36 physical dimension scales. A statistically significant difference was detected in the mental domain of the SF36 scale in the control group before the intervention with $P=.02$.

\section{Discussion}

FM raises some questions and challenges to medicine, since there are many studies that propose different theories as regards the causes and the variability of the symptoms of this disease. It lacks curative treatment and measures for pain control with drug therapy seem not to be enough, as FM is often associated with other comorbidities. The current vision of chronic diseases that include aspects of behavior change has led to a change in the approach to the disease, using a more biopsychosocial model. The authors of the European League Against Rheumatism (EULAR) guideline recognize a generalized lack of knowledge of how to prescribe non-pharmacological treatments that they attribute to the trend of using pharmacological treatments. ${ }^{15}$ New recommendations are focused on 5 priorities, one of which is the type of physical exercise most beneficial in FM: strength or aerobic training, pointing out that exercise can be of great help to improve the condition of these patients. 
Table 3. Assessment Scales Studies.

\begin{tabular}{|c|c|c|c|c|}
\hline & \multicolumn{2}{|c|}{ Intervention } & \multicolumn{2}{|c|}{ Control } \\
\hline & Pre & Post & Pre & Post \\
\hline $\mathrm{N}$ & 25 & 23 & 25 & 25 \\
\hline \multicolumn{5}{|c|}{ EVA score } \\
\hline Mean & 6.96 & 6.78 & 6.8 & 6.96 \\
\hline SD & 2.01 & 2.26 & 1.83 & 2.01 \\
\hline Sig. & $P=.578$ & $P \geq .05$ & $P=.256$ & $P \geq .05$ \\
\hline \multicolumn{5}{|c|}{ SF36 physical domain } \\
\hline Mean & 31.4346 & 32.9387 & 33.5285 & 32.8997 \\
\hline SD & 5.26515 & 5.54342 & $4.4767 I$ & 3.65973 \\
\hline Sig. & $P=.136$ & $P \geq .05$ & $P=.263$ & $P>.05$ \\
\hline \multicolumn{5}{|c|}{ SF36 mental domain } \\
\hline Mean & 31.1666 & 32.4168 & 28.844 & 29.5618 \\
\hline SD & 8.29985 & 7.69134 & 5.96263 & 4.83508 \\
\hline Sig. & $P=.136$ & $P \geq .05$ & $P=.02$ & $P<.05$ \\
\hline \multicolumn{5}{|l|}{$\mathrm{FIQ}$} \\
\hline Mean & 71.15 & 68.43 & 75.4 & 76.04 \\
\hline SD & 16.93 & 18.21 & 15.67 & 12.03 \\
\hline Sig. & $P=.648$ & $P \geq .05$ & $P=.189$ & $P \geq .05$ \\
\hline
\end{tabular}

The study's main finding was that a program of lowintensity physical exercise for 2 days a week over a 12-week period does not significantly affect pain levels, the perceived state of health or the impact of the condition. The training program was well tolerated and had no detrimental effect on the patients' health.

Nevertheless, the perception of pain and physical health measured with the SF-36 and the condition's impact improved in the intervention group and worsened in the control group, although the differences were not statistically significant. This is presumably due to the fact that the frequency of the activities, twice a week, was insufficient, though it could also be due to other factors which were not controlled for, such as other comorbidities or complex family situations.

In this respect, other studies similar to ours, which measured physical condition also based on small sample sizes and with a duration of the intervention of between 3 and 24 weeks, obtained significant improvements in several variables. However, unlike this study, the frequency of the sessions was from 3 to 5 a week. ${ }^{16-21}$

The results of our study resemble those of Van Santen in which a high and low intensity training program did not obtain significant differences in the physical condition of the 2 groups, and even led to a $20 \%$ increase in pain in the high intensity group. ${ }^{22}$

Programs involving water-based exercise seem to have be of use to these patients since there are some studies in which it is found that after only 6 weeks of training, significant improvements were obtained in terms of the FIQ, fatigue, depression, psychological well-being, anxiety, vitality and the number of tender points. ${ }^{23-25}$ Another form of physical activity also tolerated by this group is a program based on the Pilates method, 3 times a week with a duration of 12 weeks which found significant differences. However, Alentorn-Geli et al compared a traditional physical activity program with one involving a vibrating platform, with both programs involving 2 sessions per week over a 6-week period. Individuals with fibromyalgia who performed the exercises on the vibrating platform improved in terms of pain and FIQ indices; although not at levels with any statistical significance. ${ }^{26}$

The results obtained can help us to plan physical activity programs in people affected by FM, in which a 12-week duration may be insufficient and thus ineffective for obtaining significant results. In accordance with Häuser, our study did not find significant improvements in any of the variables under investigation, this could be due to carrying out an intervention with a duration of less than 12 weeks. ${ }^{10}$

Nevertheless, it is noteworthy that studies with similar characteristics to ours find significant differences in the FIQ and pain questionnaire parameters.

Our study has several inherent limitations, such as a lack of control over external factors, since we do not know if the participants engaged in other therapies or the type of pain medication they were taking. These factors were not taken into account when designing the study due to the difficulty of having homogeneous groups in these type patients.

\section{Conclusion}

The women assigned to the 2 trial groups were homogeneous in terms of the study variables. At the time they joined the trial, they were not differentiated by age, period during which they had had the condition, pain levels according to 
the EVA, the SF-36 summary measures or by the score obtained in the FIQ baseline survey.

Nonetheless, it was not observed that the intervention was effective for the main outcome variable (differences in the FIQ score) or in the other outcome variables which were analyzed (the EVA and SF-36 summary indices for health physical and mental health).

In summary, a low-intensity exercise program 2 days a week over a 12-week period had no significant effect on pain, perceived health status and the impact of the condition on a sample of women with fibromyalgia.

FM associations continue to recommend physical exercise, though few studies suggest that pain and fatigue, the condition's major symptoms, improve as a result, and patients can be severely affected by a failure to tolerate the exercises they are asked to perform.

There is no need for a specific physical activity program for patients diagnosed with fibromyalgia in primary care. However physical activity should be included as part of the day-to-day activities of these patients from the first onset of symptoms

\section{Acknowledgments}

We would like to thank the collaboration of the Unitat de Suport a la Recerca de Catalunya Central of the Institut Català de la Salut, for their support

\section{Authors' Contributions}

GS is responsible for the study coordination and obtaining funding. literature review, study design, collection, drafting and revision the manuscript. JV-A: literature review, study design, drafting and reviewing the manuscript. PR: analysis and interpretation of data, drafting and reviewing the manuscript. JM: study design, drafting and revision the manuscript. RP: coordination of patient recruitment, reviewing the manuscript. $\mathrm{XC}$ : coordination of patient recruitment, reviewing the manuscript. AR: drafting and reviewing the manuscript. $\mathrm{DB}$ is responsible for carrying out the intervention. All authors read and approved the final manuscript.

\section{Declaration of Conflicting Interests}

The author(s) declared no potential conflicts of interest with respect to the research, authorship, and/or publication of this article.

\section{Funding}

The author(s) disclosed receipt of the following financial support for the research, authorship, and/or publication of this article: Project carried out with the support of the Generalitat de Catalunya's Ministry of Health, as part of the 2016 call for grant applications as part of the Strategic Plan for Research and Innovation in Health (PERIS) 2016-2020, for Research Projects aimed at Primary Health Care. File number 7Z17/032.

\section{ORCID iD}

Glòria Sauch Valmaña iD https://orcid.org/0000-0002-1767-4314

\section{References}

1. Mas AJ, Carmona L, Valverde M, Ribas B. Prevalence and impact of fibromyalgia on function and quality of life in individuals from the general population: results from nationwide study in Spain. Clin Exp Rheumatol. 2008;26:519-526.

2. Sociedad Española de Reumatología. Estudio EPISER. Prevalencia e impacto de las enfermedades reumáticas en la población adulta española. Madrid: Sociedad Española de Reumatología; 2001.

3. Wolfe F, Smithe HA, Yunus MB, et al. The American College of Rheumatology preliminary diagnostic criteria for fibromyalgia and measurement of symptom severity. Arthritis Rheumatol. 1990;33:160-172.

4. Wolfe F, Clauw D, Fitzcharles MA, et al. Fibromyalgia criteria and severity scales for clinical and epidemiological studies: a modification of the ACR preliminary diagnostic criteria for fibromyalgia. J Rheumatol. 2011;38:1113-1122.

5. Wolfe F, Clauw DJ, Fitzcharles MA, et al. 2016 Revisions to the 2010/2011 fibromyalgia diagnostic criteria. Semin Arthritis Rheum. 2016;46:319-329.

6. Feliu-Soler A, Borràs X, Peñarrubia-María MT, et al. Costutility and biological underpinnings of mindfulness-based stress reduction (MBSR) versus a psychoeducational programme (FibroQol) for fibromyalgia: a 12-month randomised controlled trial (EUDAIMON study). BMC Complement Altern Med. 2016;16:81.

7. Bush AJ, Webber SC, Richards RS. Resistance exercise training for fibromyalgia. Cochrane Database Syst Rev. 2013;12:CD010884.

8. Departament de Salut, Generalitat de Catalunya. Pla operatiu d'atenció a les persones afectades per les síndromes de sensibilització central: fibromiàlgia, síndrome de fatiga crònica $i$ síndrome de sensibilitat química múltiple. Generalitat de Catalunya; 2016. https://www.sindromefatigacronica.org/mm/file/1807 PLA_OPERATIU_SSC_Versio\%CC\%81Definitiva.pdf

9. Thomas EN, Blotman F. Aerobic exercise in fibromyalgia: a practical review. Rheumatol Int. 2010;30:1143-1150.

10. Häuser W, Klose P, Langhorst J, et al. Efficacy of different types of aerobic exercise in fibromyalgia syndrome: a systematic review and meta-analysis of randomised controlled trials. Arthritis Res Ther. 2010;12:R79.

11. Luciano JV, Martínez N, Peñarrubia-María MT, et al. Effectiveness of a psychoeducational treatment program implemented in general practice for fibromyalgia patients: a randomized controlled trial. Clin J Pain. 2011;27:383-391.

12. Alonso J, Prieto L, Antón JM. La versión española del SF-36 Health Survey (Cuestionario de salud SF-36): un instrumento para la medida de los resultados clínicos. Med Clin (España). 1995;104:771-776.

13. Rivera J, Gonzalez T. The Fibromyalgia Impact Questionnaire: a validated Spanish version to assess the health status in women with fibromyalgia. Clin Exp Rheumatol. 2004;22:5554-5560.

14. Monterde S, Salvat I, Montull S, Fernandez-Ballart J. Validación de la versión española del Fibromyalgia Impact Questionnaire. Rev Esp Reumatol. 2004;31:507-513.

15. Macfarlane GJ, Kronisch C, Dean LE, et al. EULAR revised recommendations for the management of fibromyalgia [published online July 4, 2016]. Ann Rheum Dis. doi:10.1136/ annrheumdis-2016-209724 
16. García-Martínez AM, de Paz JA, Márquez S. Effects of an exercise programme on self-esteem, self-concept and quality of life in women with fibromyalgia: a randomized controlled trial. Rheumatol Int. 2012;32:1869-1876.

17. Harden RN, Song S, Fasen J, et al. Home-based aerobic conditioning for management of symptoms of fibromyalgia: a pilot study. Pain Med. 2012;13:835-842.

18. Hooten WM, Qu W, Townsend CO, Judd JW. Effects of strength vs aerobic exercise on pain severity in adults with fibromyalgia: a randomized equivalence trial. Pain. 2012;153:915-923.

19. Kayo AH, Peccin MS, Sanches CM, Trevisani VF. Effectiveness of physical activity in reducing pain in patients with fibromyalgia: a blinded randomized clinical trial. Rheumatol Int. 2012;32:2285-2292.

20. Sañudo B, Galiano D, Carrasco L, de Hoyo M, McVeigh JG. Effects of a prolonged exercise program on key health outcomes in women with fibromyalgia: a randomized controlled trial. J Rehabil Med. 2011;43:521-526.

21. Sañudo B, Carrasco L, de Hoyo M, McVeigh JG. Effects of exercise training and detraining in patients with fibromyalgia syndrome: a 3-yr longitudinal study. Am J Phys Med Rehabil. 2012;91:561-569.

22. Van Santen M, Bolwijn P, Verstappen F, et al. A randomized clinical trial comparing fitness and biofeedback training versus basic treatment in patients with fibromyalgia. $J$ Rheumatol. 2002;29:575-581.

23. Evcik D, Yigit Y, Pusak H, Kavuncu V. Effectiveness of aquatic therapy in the treatment of fibromyalgia syndrome: a randomized controlled open study. Rheumatol Int. 2008;28:885-890.

24. Cedraschi C, Desmeules J, Rapiti E, et al. Fibromyalgia: a randomised, controlled trial of a treatment programme based on self management. Ann Rheum Dis. 2004;63:290-296.

25. Altan L, Korkmaz N, Bingol U, Gunay B. Effect of pilates training on people with fibromyalgia syndrome: a pilot study. Arch Phys Med Rehabil. 2009;90:1983-1988.

26. Alentorn-Geli E, Padilla J, Moras G, Lázaro Haro C, Fenández-Solà J. Six weeks of whole-body vibration exercise improves pain and fatigue in women with fibromyalgia. $J$ Altern Complement Med. 2008;14:975-981. 